\title{
Feminismo Decolonial, Perspectiva dos Funcionamentos e Educação
}

Maria Clara Dias

Letícia Gonçalves ${ }^{2}$

Resumo: O objetivo deste texto é propor um modelo de justiça adequado a um sistema educacional, amplo e inclusivo, no que se refere às múltiplas e complexas manifestações de sexualidade e gênero. Toma o Feminismo Decolonial, sobretudo as contribuições da autora Ochy Curiel, como uma abordagem crítica de leitura da realidade, e defende a Perspectiva dos Funcionamentos, de Maria Clara Dias, como teoria de justiça coerente com o contexto em questão.

Palavras-chave: Educação; Perspectiva dos Funcionamentos; Feminismo Decolonial.

\section{Decolonial Feminism, the Functionings Approach and Education}

\begin{abstract}
The purpose of this text is to propose a model of justice that is adequate to a broad and inclusive educational system, in the multiple and complex manifestations of sexuality and gender. It takes Decolonial Feminism, especially the contributions of the author Ochy Curiel, as a critical approach on the reading of reality and defends the Functioning Approach, of Maria Clara Dias, as a theory of justice consistent with the context in question.
\end{abstract}

Keywords: Education; Functioning Approach; Decolonial Feminism.

${ }_{1}^{1}$ Professora Titular do Departamento de Filosofia da UFRJ. mcdias1964@gmail.com

${ }^{2}$ Mestre em Psicologia. Doutoranda em Bioética, Ética Aplicada e Saúde Coletiva, pela UFRJ, Fiocruz, UERJ e UFF. leticia1goncalves@yahoo.com.br 


\section{INTRODUÇÃO}

O objetivo deste texto é contribuir para uma análise e uma proposição de justiça concernentes às questões de sexualidade e gênero, no contexto da Educação. A recusa a compreender as diferenças e desigualdades que compõe os sujeitos na sociedade e, portanto, também nas instituições de educação, e as violências que envolvem tal recusa, são responsáveis pela produção de sofrimentos e injustiças que podem ser evitados. Não há justificativa moral para a não implementação de medidas neste sentido e, ainda menos, para a manutenção de iniciativas que intensifiquem tais sofrimentos. Discutir gênero e Educação é um exercício necessário e complexo, sobretudo, em um período em que tais temas têm suscitado intensos embates na arena pública e política. O potencial simbólico da Educação, circunscrita às instituições de ensino, justifica a mobilização de interesses e forças de ordens variadas, principalmente, quando consideramos sua relação privilegiada com desenvolvimento das subjetividades, nos primeiros ciclos escolares, e a importância destes na socialização secundária. Tomaremos como ponto de partida para discussão o projeto de lei nº7180/2004, que propõe o movimento “escola sem partido", com enfoque na exclusão do que tem sido denominado por seus defensores de "ideologia de gênero", entendida como uma espécie de "ideologia de orientação sexual" na Educação. Embora o projeto tenha adquirido contornos mais amplos, este ponto permanece sendo central nas discussões vigentes.

Partindo do reconhecimento da relevância estrutural da Educação para uma sociedade, pretendemos fornecer uma leitura do projeto "escola sem partido" como manifestação e/ou sintoma da hegemonia heterossexual vigente, que impõe padrões de comportamento, com uma falsa pretensão de universalidade, a todos os segmentos da sociedade. Para tal, traçaremos um paralelo entre a proposta em questão e a leitura realizada por Ochy Curiel (2013), acerca da Constituição Federal da Colômbia. Apresentaremos, em linhas gerais, o Feminismo Decolonial como uma teoria crítica capaz de auxiliar na descolonização teórica e epistemológica de referenciais que reclamam um falso viés de neutralidade. $\mathrm{O}$ trabalho realizado por Curiel fornecerá o subsídio necessário a nossa defesa de que a crítica apresentada pelo referido projeto de lei, ao que localiza como imposição de uma "ideologia de gênero", possui, ao contrário, explícito caráter de imposição de uma perspectiva hegemônica, pautada em uma leitura ideológica binária e cissexual da sexualidade humana. Deste modo, partimos da hipótese de que a proposta "escola sem partido" corrobora com a manutenção e aprofundamento de estruturas de perpetram desigualdades e violências indefensáveis, sob o ponto de vista de uma concepção de justiça ou de uma moralidade mais inclusiva. Propomos, por fim, a Perspectiva dos Funcionamentos (DIAS; 2015, 2016) como teoria que poderá contribuir para a ampliação da justiça no contexto da Educação. 


\section{FEMINISMO DECOLONIAL COMO TEORIA CRÍTICA}

As teorias decoloniais fornecem um instrumental de análise crítico dos embates que envolvem classe, raça e gênero, o que nos possibilita pensar de modo aprofundado a relação entre gênero e Educação nas diversas sociedades. Partiremos, aqui, de uma breve contextualização de tais teorias, a fim de resgatar alguns de seus elementos centrais e promover uma leitura mais coerente das relações e questões próprias à sociedade brasileira.

O termo colonialismo foi designado, a princípio, para nomear um tipo específico de estratégia de dominação geopolítica datada entre os séculos XVI e XVIII. Lógica que foi ampliada no século XIX, com a ênfase na busca de mercados consumidores para o excedente de capital e rebatizada de imperialismo ou neocolonialismo. Neste processo, a ideia de raça surgiu como um eixo fundamental da colonialidade do poder, como modo de classificação social (QUIJANO, 2000) para atribuir diferenciação biológica prévia, que, posteriormente, passou a ser defendida em termos hierárquicos naturalizados. A possibilidade de dominação e exploração se sustentou em teorias racistas baseadas na ideia de superioridade do branco europeu e inferioridade de povos africanos, asiáticos e latinos americanos.

O Feminismo Decolonial aprofundou e estendeu tal análise ao gênero, defendendo a inseparabilidade da raça, classe e gênero como complexos sistemas que se cruzam na produção de opressões e manutenção das diversas estruturas de exploração (LUGONES, 2008; MOHANTY, 2008; BIDASECA, 2011). Estas feministas extraem dos estudos sobre colonialidade a compreensão do etnocentrismo ocidental como padrão superior que constrói as demais culturas e povos como o outro inferior. Este mecanismo, que se efetiva, sobretudo, com a homogeneização de povos com diferentes histórias, linguagens, memórias e identidades, tem também repercussões no que se refere ao campo da sexualidade e o apagamento das multiplicidades.

Uma importante teórica do feminismo decolonial, Chandra Mohanty, analisa o colonialismo de um ponto de vista discursivo, localizando amplos sistemas de manutenção de estruturas hierárquicas. Ainda que o termo colonização possua distintas concepções, que apontam para fenômenos diversos, a tônica de Mohanty (2008) é no seu efeito de eliminação ou, de modo mais velado, ocultamento da heterogeneidade dos sujeitos. A recusa ao reconhecimento plural se conecta, portanto, com a manutenção de hierarquias, uma vez que estabelece as referências normativas e subalterniza o que foge a estas. Deste modo o Feminismo Decolonial oferece uma crítica ao pretenso sujeito universal abstrato, marcadamente situado em uma lógica patriarcal, cisheterocentrada, racista, elitista, urbana e especista; e localiza complexos sistemas de opressão, dominação e exploração, que se entrecruzam, limitando a implementação de uma concepção ampliada de justiça. Partindo destes aspectos, Ochy Curiel enfatiza o projeto heteronormativo da manutenção da colonialidade e oferece uma perspectiva crítica de análise institucional e política presentes organicamente em propostas como a manifesta no projeto "escola sem partido", como discutiremos a seguir. 


\section{O PROJETO DE EDUCAÇÃO HETEROSSEXUAL}

O projeto "escola sem partido" assume uma roupagem de neutralidade e se coloca contra uma suposta ideologização de gênero que se daria nos espaços de educação escolar. De modo destacado, o que está em questão, evidenciado também pelos enfrentamentos a implementação do programa "Brasil sem homofobia", é a negação da diversidade sexual e de gênero que compõe a sociedade. O projeto de lei 7180-2014 propõe alterar o art. 3o da lei n. 9.394, de 20 de dezembro de 1996, “[...]para incluir entre os princípios do ensino o respeito às convicções do aluno, de seus pais ou responsáveis, dando precedêcia aos valores de ordem familiar sobre a educação escolar nos aspectos relacionados à educação moral, sexual e religiosa". (BRASIL,2014).

O projeto teve apensadas seis proposições, cinco favoráveis, como o Projeto de lei (PL) n. 867 2015, que acrescenta um parágrafo único ao artigo 3 da Lei n. 394 (Lei de diretrizes e Bases da Educação Nacional) para prever a proibição de adoção de formas tendentes à aplicação de "ideologia de gênero" ou orientação sexual na Educação. A única proposição contrária ao projeto foi de autoria do Deputado Jean Wyllys, o PL n. 6.005, de 2015, que institui o programa "Escola livre" em todo o território nacional. O PL n. 867-2015 menciona que a Educação atenderá ao seguinte princípio: "I - neutralidade política, ideológica e religiosa do Estado”. Nas justificativas, o deputado proponente explica suas razões:

É fato notório que professores e autores de livros didáticos vêm-se utilizando de suas aulas e de suas obras para tentar obter a adesão dos estudantes a determinadas correntes políticas e ideológicas; e para fazer com que eles adotem padrões de julgamento e de conduta moral - especialmente moral sexual - incompatíveis com os que lhes são ensinados por seus pais ou responsáveis." (BRASIL, 2015 p.5, grifo nosso)

Por esta perspectiva, conteúdos envolvendo a diversidade sexual e de gênero nas escolas representariam uma ideologia moralmente condenável pelo que consideram "o padrão de família brasileira". Ao contrário do proposto, a inclusão de tais temas nas escolas, por vezes de modo incipiente e insatisfatório, objetiva não o disciplinamento sexual de estudantes, mas, tão somente, a ampliação do reconhecimento e respeito às diversidades. Neste sentido, uma teoria crítica nos permite questionar em que tal proposta representaria um problema ou afronta a qualquer pessoa ou coletivo, chegando a ser considerada "incompatível com os ensinamentos de pais e responsáveis", de modo genérico. O trecho acima exposto, a exemplo dos demais envolvendo o projeto "escola sem partido", revela que seu proponente, ao se colocar como representante de pais e responsáveis, toma uma noção abstrata que aponta para a imposição de uma norma hegemônica. Neste ponto, a análise da constituição colombiana realizada por Ochy Curiel, torna-se bastante útil para melhor compreendermos este fenômeno brasileiro. O paralelo com a Educação faz-se possível, dada sua relevância na produção de subjetividades, relações sociais e sentidos, constituindo uma arena, especialmente simbólica, de disputa pela hegemonia. 
A heterossexualidade é uma prática ou uma expressão sexual, dentre outras, porém possui um caráter político, na medida em que é apresentada como hegemônica. Como instituição política, a heterossexualidade está comprometida com o patriarcado e, portanto, sustenta a tese de incompletude das mulheres, como uma falta ou um problema, e a complementariedade binária dos gêneros. Curiel (2013) analisou o texto da Constituição política colombiana de 1991 para mostrar como se expressa o regime da heterossexualidade no país, ou seja, como a heterossexualidade como regime político se relaciona com a construção da nação. A Constituição, conforme indica a autora, sintetiza a ideologia hegemônica de um país e também um certo consenso jurídico, teórico e político de determinados atores, atrizes e grupos que atuaram na sua formulação.

Curiel (2013) adota a noção de hegemonia cultural de Antonio Gramsci (1975) e destaca uma concepção de dominação, entendida como o poder exercido pela classe dominante através da imposição de suas ideologias, cuja finalidade é a manutenção de um determinado sistema de relações, no caso de Gramsci, o capitalismo. Tal processo tende a ser sutil e se dá de modo a que a maior parte do conjunto social, inclusive as pessoas que não compõe aquele conjunto hegemônico, assimilem tal ideologia e passem a partilhar da mesma, o que se aplica ao caso da heterossexualidade normativa e compulsória. Trata-se, assim, da imposição de um particular que se transveste de universal.

Para pensar a heterossexualidade como uma instituição política e, como pretendemos mostrar, uma ideologia, Curiel (2013) partiu das análises de Adrienne Rich (1980), autora responsável pela produção do conceito de heterossexualidade compulsória. Para Rich (1980), além da heterossexualidade, a família nuclear, a maternidade e a exploração econômica são instituições pautadas em ideologias que reduzem o poder das mulheres. A autora aprofundou sua tese com o que nomeou de "ideologia do romance heterossexual", cujo processo de naturalização se efetiva através mecanismos diversos, introduzidos desde a infância, como os contos de fadas, e que passam a integrar todo contexto educacional. Tal ideologia visa naturalizar o desejo das mulheres pelos homens e, podemos acrescentar, naturalizar também o desejo dos homens pelas mulheres, ainda que, neste último caso, possa não existir uma relação de dependência, do ponto de vista da realização de si. Na compreensão da autora, este modo de prescrever a sexualidade estaria também relacionado com a manutenção da exploração do trabalho das mulheres em funções não remuneradas, como babá, cozinheira, faxineira, secretarias de seus maridos etc. Na concepção de Rich (1980), a imposição institucional da heterossexualidade às mulheres sobressai à possibilidade de leitura desta como mais uma "experiência sexual".

Curiel (2013) destaca que a diferença sexual é um fundamento central do pacto heterossexual, ou seja, que a definição binária, fixa e enquadrada, do que é ser uma mulher e do que é ser um homem, está associada à ideia de complementariedade entre ambos. Deste modo, a "heteronação", ao tomar esta posição como hegemônica, a reconhece e legitima, produzindo lógicas de marginalização e exclusão. A autora introduz o conceito de heteronação, como parte do pacto social; como algo que é produzido por discursos institucionais e jurídicos que visam prescrever a heterossexualidade como norma e ocultar as 
diferenças existentes na sociedade. Como evidenciado, os pactos sociais são produtos da hegemonia. A hegemonia, por sua vez, por não ser estática e por encontrar resistência, precisa constantemente se renovar e se afirmar. Do mesmo modo, para se manter, ela necessita da ocorrência de consentimentos, ainda que oculte coerções.

O projeto "escola sem partido" parece refletir exatamente uma tentativa de reafirmação do pacto social-heterossexual. Partindo desta compreensão, a proposta expressa por seu conteúdo de recusa de ideologias e adoção de total neutralidade, apenas traveste uma ideologia hegemônica, sistematicamente alimentada por mecanismos de opressão e segregação de formas de vida andro-hetero-cis-discordantes. O Feminismo Decolonial, enquanto teoria crítica, denuncia sistemas políticos que promovem opressões e injustiças sistêmicas. Dando continuidade a esta crítica, pretendemos avançar e propor uma perspectiva específica de justiça mais inclusiva, a saber, a Perspectiva dos Funcionamentos (DIAS, 2015).

\section{A PERSPECTIVA dOS FUNCIONAMENTOS E A EDUCAÇÃo}

A Perspectiva dos Funcionamentos $(\mathrm{PdF})$ procura defender uma concepção de moralidade mais inclusiva e comprometida com um ideal de justiça igualitário e universal, capaz de garantir respeito e consideração a todos os indivíduos. A universalidade aqui não se caracteriza pela referência a padrões, entidades ou procedimentos abstratos e formais, mas pela pretensão de abarcar, sempre, a totalidade dos envolvidos, rompendo as barreiras do racismo, do colonialismo, do androcentrismo, da heteronormatividade e do próprio especismo. Diferentemente da lógica hegemônica que visa ocultar as diferenças, tal proposta recusa modelos normativos abstratos de caracterização dos concernidos, e, no contexto da Educação, ao centrar-se no florescimento dos diversos indivíduos, permite a ampliação do reconhecimento das diversas expressões da sexualidade. A PdF procura identificar os concernidos pelo nosso discurso moral e o foco sob o qual todos os indivíduos devam ser considerados como igual objeto de respeito. Ela não investiga propriamente as razões das exclusões e das desigualdades, mas endossa a crítica aos diversos sistemas de opressão que impedem o florescimento das diferentes formas de existência. Neste sentido, a PdF endossa a crítica realizada pelo Feminismo Decolonial aos sistemas vigentes.

Para alcançar a abrangência almejada, a PdF irá promover uma distinção entre agentes e concernidos morais, sendo estes últimos caracterizados, simplesmente, como sistemas funcionais. Desta forma, a PdF promove um deslocamento do referencial teórico tanto de perspectivas de base contratualista - que se sustentam no duplo atributo da racionalidade/liberdade -, como de perspectivas utilitaristas, cujo critério de inclusão é também uma capacidade ou funcionamento específico, a saber, a capacidade de experienciar o prazer e a dor, ou seja, a senciência. Do mesmo modo, permite estender o escopo da moralidade a outros sistemas funcionais, tais como o meio ambiente e alguns objetos 
inanimados, estes últimos entendidos como sistemas acoplados (DIAS, 2016), objetos caracterizados, na PdF, como parte indissociável da totalidade de sistemas que integram nossa própria identidade.

Busca-se, assim, uma nova ordenação das prioridades que não estabeleça hierarquias prévias baseadas em atributos naturais, sociais ou econômicos -, injustificáveis sob o ponto de uma moral que se quer cada vez mais inclusiva. As prioridades admitidas serão aquelas que correspondem aos elementos centrais para que cada indivíduo tenha a chance de viver uma vida plena ou realizada, seja ele racional, livre, senciente ou não. Desta forma, a PdF poderá convergir com uma perspectiva Feminista Decolonial que reconheça, para além das opressões de gênero e do imperialismo, seja ele racial, cultural, religioso ou epistêmico, a opressão especista.

Aliada a uma ampla frente de combate a todas as possíveis formas de opressão e dominação, a PdF insiste na pretensão de universalidade do princípio moral do respeito.Trata-se, portanto, de uma perspectiva moral universalista, mas que não adere à concepção abstrata, desencarnada e desenraizada do agente e concernido moral. O princípio universal do respeito, aqui, exige que investiguemos, em cada caso, para cada indivíduo, em que consiste o seu bem viver ou, na terminologia da Pdf, quais são e como podemos promover os seus funcionamentos básicos. A dominação e a opressão são formas de violência que impedem o florescimento de qualquer indivíduo. Quaisquer que sejam suas causas históricas ou estruturais, elas são moralmente condenáveis e devem, portanto, ser criticadas e combatidas. Do mesmo modo, a imposição de um padrão de sexualidade hegemônico, tal qual a heterossexualidade, inibe demandas, desejos e formas de expressão dissonantes e, com elas, a realização de formas de vida diversas. A simples insistência no uso de categorias triviais como "meninos" e "meninas", reproduz e reifica o binarismo, aniquilando outras formas não-binárias de existência.

As Teorias Decoloniais apontam para a fixação e fortalecimento de estruturas interseccionais de poder e opressão que, como tentamos mostrar, incidem, também, e, sobretudo, sobre o sistema educacional. Trata-se de um ordenamento histórico de indivíduos a partir de seu pertencimento a uma religião, raça, classe social e gênero. Guacira Lopes Louro (1997) discute de modo interessante os ordenamentos e hierarquizações que organizaram o modelo de escola herdado da sociedade ocidental moderna, que além da separação de católicos e protestantes, ricos e pobres, também separou meninos e meninas. A autora parte de abordagens pós-estruturalistas para desnaturalizar a organização escolar, pautada na naturalização da diferença entre os sexos. Louro convoca à problematização do conteúdo, da forma e das teorias que sustentam os trabalhos nas escolas. Em vários de seus textos sobre gênero e educação, ela colabora com o desvelamento do binarismo de gênero oculto no funcionamento das escolas, o que seria, de fato, a ideologização de gênero, pautado em estereótipos.

A implementação da PdF no âmbito da educação deverá estar pautada em uma investigação empírica das demandas existentes e dos fatos que impedem sua plena realização. Aqui, apesar de insistirmos na necessidade de estarmos atentos à especificidade das demandas geradas por cada indivíduo, precisamos assumir que, sob o ponto de vista da geração de políticas públicas, a alternativa será identificar 
demandas compartilhadas e buscar mecanismos que busquem satisfazê-las de modo mais eficaz. No tocante ao paradigma proposto pela PdF para a geração de políticas públicas, além da ênfase na investigação empírica, destaca-se a necessidade de formas diferenciadas de escuta e identificação das demandas. Professores e demais membros (as) das instituições educacionais deverão então incorporar na sua atuação e intervenções um modo de escuta e sensibilidade mais apurados. Isso porque, ao não assumir a capacidade de escolha como característica dos concernidos, a PdF permite a inclusão de indivíduos pouco ou nada racionais e pouco ou nada autônomos. Indivíduos, portanto, cuja forma de expressão pode passar ao largo de um observador pouco atento e/ou com uma ótica viciada através de lógicas colonizadas e colonizatórias, que compromete sua capacidade de compreender o seu entorno e, nele, os diversos sistemas funcionais que clamam por sua forma própria de realização.

\section{CONCLUSÃO}

Reconhecer e enfrentar os mecanismos de produção de violências e sofrimentos na educação precisa ser um compromisso amplo de vários setores e atores na promoção de uma sociedade mais justa e inclusiva, em relação à multiplicidade que compõe as subjetividades humanas. O Feminismo Decolonial nos permite desvelar mecanismos de dominação que se apresentam atualmente no contexto político brasileiro e, simultaneamente, positivar identidades de gênero discordantes daquelas cisheteronormativas. A Perspectiva dos Funcionamentos insiste no reconhecimento de que cada indivíduo apresenta demandas básicas específicas, que precisam ser igualmente respeitadas, afim de que possamos construir um espaço democrático, de respeito às singularidades, consonante com a pretensão de uma perspectiva moral universalista.

Embora tenhamos mencionado apenas uma mobilização contrária a ampliação do reconhecimento da pluralidade na educação, gostaríamos de concluir destacando uma estratégia contrária, importante para a descolonização dos currículos. Trata-se da criação, em 2003, da Lei 10.639, que “altera a Lei n 9.394, de 1996, que estabelece as diretrizes e bases da educação nacional, para incluir no currículo oficial da Rede de Ensino a obrigatoriedade da temática "História e Cultura Afro-Brasileira" (BRASIL, 2003). A lei objetiva o resgate das contribuições econômicas, políticas e sociais do povo negro no Brasil, destacando a inclusão nas áreas de Educação Artística e Literatura e História do Brasil, definindo que tais conteúdos deverão ser incluídos em todo o currículo escolar. A Lei evidencia uma compreensão da educação nas instituições de ensino, para além do modelo curricular conteudista, e traz consigo um potencial de descolonização das subjetividades. 


\section{Referências}

BIDASECA, Karina. Mujeres blancas buscando salvar a mujeres color café: desigualdade, colonialismo jurídico y feminismo postcolonial. Andamio - Revista de Investigación Social, vol. 8, núm. 17, , p. 61-89, 2011

BRASIL. Lei n".1 (60)9. de 9 de janeiro de 2003. Altera a que estabelece as diretrizes e bases da educação nacional. Diário Oficial (da) República Federativa do Brasil, Brasília, DF, 10jan. 2003. Disponível em $<$ http://www.senado.gov.br>. Acesso em 25 de outubro de 2018.

CURIEL, Ochy. La nación heterosexual: análisis del discurso jurídico y el régimen heterosexual desde la antropologia de la dominación. Bogotá: Brecha lésbica y en la frontera, 2013.

DIAS, Maria Clara. (org.) A perspectiva dos funcionamentos: por uma abordagem moral mais inclusiva. Rio de Janeiro: Pirilampo, 2015.

DIAS, Maria Clara. Sobre nós: expandindo as fronteiras da moralidade. Rio de Janeiro: Pirilampo, 2016.

GRAMSCI, Antonio. El materialismo histórico y la filosofía de Benedetto Croce. México: Juan Pablo Editor, 1975.

LOURO, Guacira Lopes. Geêero, sexualidade e educação: uma perspectiva pós-estruturalista. Petrópolis, RJ: Vozes, 1997.

LUGONES, María. Colonialidady Género. Bogotá: Tabula Rasa, N.9, p. 73-101, 2008.

MOHANTY, Chandra Talpade. Bajo los ojos de occidente: academia feminista y discurso colonial. In, NAVAZ, Liliana Suárez; HERNÁNDEZ, Aída (eds.). Descolonizando el feminismo: teorias y prácticas desde los márgenes, Madrid: Editora Cátedra, 2008.

QUIJANO, Aníbal, 2000, Colonialidad del poder y clasificación social, Journal of world-systems research, vi, 2, Summer/Fall, 2000, p. 343. http://cisoupr.net/documents/jwsr-v6n2-quijano.pdf

Rich, Adrienne. La heterosexualidad obligatoria y la existencia lesbiana. In, NAVARRO, Marysa; STIMPSON, Catherine R. (orgs.). Sexualidad, género y roles sexuales. Buenos Aires: Fondo de Cultura Económica. p. 36-64, 1998.

BRASIL. Congresso - Comissão Especial Escola sem Partido. Projeto de Lei 7180/14 Disponível em: $<\underline{\text { https://www.camara.gov.br/proposicoesWeb/prop mostrarintegra?codteor }=1661955 \text { \&filename }=V T}$ $\underline{\mathrm{S}+1+\mathrm{PL} 718014+\% 3 \mathrm{D} \% 3 \mathrm{E}+\mathrm{PL}+7180 / 2014>}$. Acesso em: 10 de outubro de 2018. 